\title{
Fecal Pellet Counts as a Technique for Monitoring an Alpine-Dwelling Social Rodent, the Hoary Marmot (Marmota caligata)
}

\author{
Tim J. Karels*† \\ Lori Koppel* and \\ David S. Hik* \\ *Department of Biological Sciences, \\ University of Alberta, Edmonton, Alberta, \\ T6G 2E9, Canada \\ $\dagger$ Present address: Department of Biological \\ Sciences 331 Funchess Hall, Auburn \\ University, Auburn, Alabama 36849-5415, \\ U.S.A. \\ kareltj@auburn.edu
}

\begin{abstract}
We evaluated fecal pellet counts as an index of hoary marmot (Marmota caligata) social group size in order to develop a simple, inexpensive method for monitoring population change of a widely distributed, but poorly studied alpine mammal. Fecal pellet counts were conducted in three separate seasons along several $2 \mathrm{~m} \times 100 \mathrm{~m}$ transects located parallel to and 10, 20, and $30 \mathrm{~m}$ from the edge of alpine boulderfields (talus) occupied by marmots. Marmot activity and location relative to talus was also determined to assess the proportion of time spent foraging as a function of distance from refuge. Marmots spent $74 \%$ of their activities in meadows at a mean distance of $11.6 \mathrm{~m}$ from talus, and activity in meadows declined with increasing distance from talus, as did fecal pellet counts. Fecal counts at $10 \mathrm{~m}$ from the edge of talus were strongly and linearly related $\left(r^{2}=0.89\right)$ to marmot abundance. The functional equation of marmot abundance predicted marmot abundance in five independent social groups within $17 \%$ of the observed group size. Fecal pellet counts appear to provide a precise index of marmot group size suitable for long-term monitoring of population change.
\end{abstract}

\section{Introduction}

Testing ecological theory in the field and managing wildlife populations and their habitat requires reliable estimates of population density among sites and over time (McArdle et al., 1990; Caughley and Sinclair, 1994; Wilson et al., 1996). Compared with direct enumeration techniques, such as transect counts or mark-recapture estimates, population indices often provide an inexpensive, nonintrusive, and time-efficient alternative for measuring population change. These indices vary in precision from ranking relative abundance (e.g., Chitty, 1948, 1950; Litvaitis et al., 1985b) to correlated and predictive measurements of absolute abundance (Krebs et al., 1987; Hochachka et al., 2000; Morneau and Payette, 2000). One relatively simple method, fecal pellet counts, has been widely adopted to estimate population density and habitat use for lagomorphs (Litvaitis et al., 1985a; Krebs et al., 1987; Rogowitz, 1988; Krebs et al., 2001), ungulates (Neff, 1968; Fuller, 1991; Lehmkuhl et al., 1994; Wemmer et al., 1996), macropods (Johnson and Jarman, 1987; Vernes, 1999), and elephants (Barnes, 2001). However, the suitability of this technique for other species, particularly rodents and semifossorial mammals, is largely untested.

The population size of burrowing rodents has been correlated with burrow counts (Owings and Borchert, 1975; Biggins et al., 1993) or burrow activity (Lord et al., 1970; Schmutz and Hungle, 1989; Hubbs et al., 2000), with mixed results. For example, Van Horne et al. (1997) cautioned that burrow counts are a poor index of Townsend's ground squirrel (Spermophilus townsendii) abundance for two reasons. First, their burrows are used by many species and hence difficult to assign ground squirrel activity, and second, burrows may persist longer in some habitats than others thus giving the appearance of more squirrels. Behavioral factors that change with population density, such as burrow sharing among individuals or mobility, can also be problematic in developing precise indices (Hubbs et al., 2000).

These potential biases suggest that burrow counts or burrow activity might not be useful for estimating abundance of highly social species (e.g. Marmota spp.), because group members often share large central dens (Barash, 1973; Holmes, 1984a; Arnold, 1990; Blumstein and Arnold, 1998). We assessed the accuracy of fecal pellet counts in meadows as an index of social group size in hoary marmots (Marmota caligata) in order to develop a quick, nonintrusive, and inexpensive method, which could even be conducted by amateur observers, to monitor marmot population change in alpine ecosystems.

\section{Methods}

We studied hoary marmot social groups within a 4-km² study area above treeline in an alpine valley in the southwest Yukon, Canada (Hik et al., 2001). The habitat consists of 0.07- to 15.7-ha talus patches separated by 15 to $1140 \mathrm{~m}$ of meadow (Franken and Hik, 2004). Marmot burrows are predominantly in the talus patches which provide shelter from predators and weather. Most of the entrances are not easily identified as burrows since they simply appear as spaces between and under large boulders. Hence counting burrows to estimate marmot abundance is not practical. There is little if any food within the talus patches and so marmots must forage in the adjacent meadows. From May to August 1999 to 2002 we live-captured, marked and released all marmots in the population. Traps $(66 \times 23 \times 23 \mathrm{~cm}$ and $107 \times 38 \times 51 \mathrm{~cm}$; Tomahawk Live Trap Company, Tomahawk, WI) were baited with urine (Holmes, 1984b) and live vegetation from the adjacent alpine meadows, including sedges (Carex spp.) and herbs (e.g. Artemisia spp.) that are part of their normal diet (Hansen, 1975; Holmes, 1984b).

Juveniles emerged during a 2-wk period in early to mid-July and were counted upon emergence. Juveniles are difficult to trap within the first $2 \mathrm{wk}$ after emergence and therefore were noosed about the neck with nylon-coated stainless steel braided wire (60-lb test fishing line) fixed to the end of a 4-m telescopic fiberglass pole. Live-traps were used to capture juveniles after $2 \mathrm{wk}$ postemergence. At first capture, marmots were marked in each ear with No. 3 monel tags (National Band and Tag, Newport, Kentucky) and a small piece of colored wire 


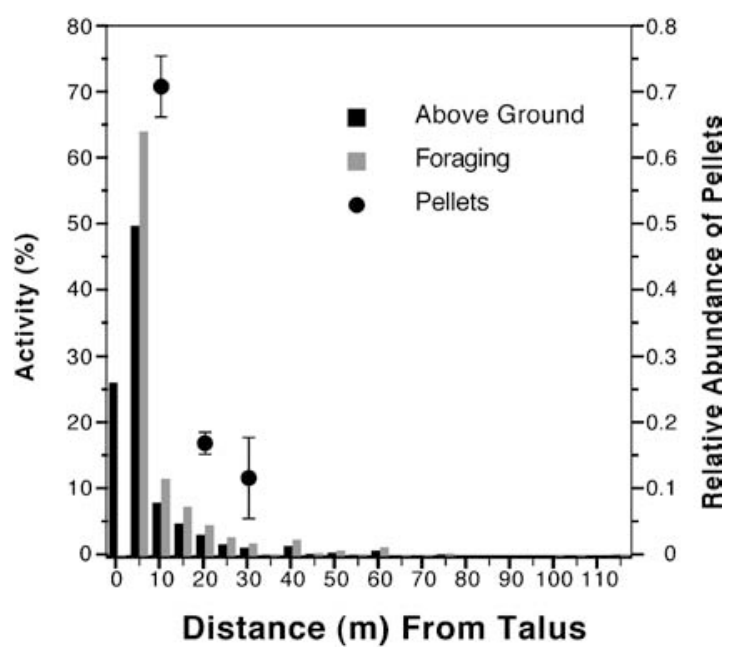

FIGURE 1. Relative frequency of aboveground activity, foraging, and pellet deposition by hoary marmots (Marmota caligata) in the southwestern Yukon Territory, Canada, from early July to mid-August 2001 with increasing distance from talus.

to facilitate individual identification at distances less than $50 \mathrm{~m}$. A unique letter/number combination was dyed (various brands) into the fur above the tail of each animal to allow for individual identification at distances up to $200 \mathrm{~m}$ with binoculars $(8 \times)$. Colored wires were replaced annually due to fading and chewing, and faded dyed markings were reapplied at subsequent recaptures.

We are confident of completely enumerating each social group. Every social group was trapped over the course of 2 to $3 \mathrm{~d}$ approximately every $1.5 \mathrm{wk}$. Field personnel also recorded marked and unmarked marmots each day, and an average of 975 marmot sightings were recorded each year from 1999 to 2002. Intensive capturing, recapturing, marking and resighting allowed us to determine that all marmots in the social groups within this study were marked by August 2000 with the exception of one adult male that remained unmarked until August 2001. Marmots are easily observed because of their large size and diurnal activities and therefore we are confident that we did not exclude any individuals.

Marmots from five social groups were observed in 40 1-h sessions from 9 July to 16 August 2001 to determine their distribution and activity over increasing distances from talus. We observed marmots through binoculars $(8 \times)$ from vantage points either upslope or across the valley from the social group and typically $>100 \mathrm{~m}$ away from the center of their activity. Observations were conducted early to mid-day (900 to 1300 PST) or in late afternoon to early evening (1600 to 2100 PST) when marmots are typically active (Holmes, 1979). For all visible marmots, we recorded their distance and activity every three minutes from their first appearance aboveground during the session until they disappeared belowground or the session ended, whichever came first. We estimated (to the nearest $5 \mathrm{~m}$ ) distance from talus by comparing the marmot's location with a permanent surveyed grid with $1-\mathrm{m}$ tall wooden stakes at 50-m intervals. For the purpose of this study, we divided all recorded activities into two categories, foraging and other aboveground activity (e.g., resting, traveling, and playing). No activities were recorded for marmots when they were belowground.

We conducted pellet counts mid-August each year from 2000 to 2002 for the five social groups that had been previously enumerated by live-trapping. In 2002, we conducted pellet counts in an additional five social groups in our study area in order to test the predictive equations of marmot abundance. Pellet transects were $2 \mathrm{~m} \times 100 \mathrm{~m}$ running straight and approximately parallel to the edge of the talus margin

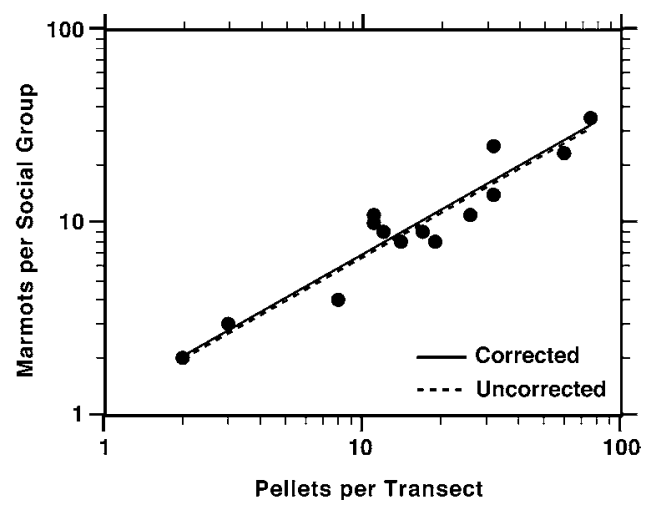

FIGURE 2. Regression of hoary marmot (Marmota caligata) social group size on the abundance of pellets per $2 \mathrm{~m} \times 100 \mathrm{~m}$ transect in southwest Yukon Territory 2000-2002.

within a marmot social group's home range. All the current season's pellets were counted (see Murie [1974] for description of pellets). Pellets from the previous year are rare and easily identified from their state of decomposition in comparison to the current season's pellets, which remain intact until winter. Barash (1980) observed that hoary marmots feed at an average distance of $5-11 \mathrm{~m}$ from their burrows; therefore we located our transects within this range. Since maintaining a constant distance from the talus was difficult owing to the nonlinear talus-meadow border, the $100-\mathrm{m}$ transect was divided into two $50-\mathrm{m}$ sections when necessary. In 2001, pellet counts were conducted at approximate 10,20 , and 30-m intervals to assess the distribution of pellets with increasing distance from the talus. Counting pellets within talus was not practical as rocks can obscure pellets.

Linear regression and paired $t$-tests were performed according to the procedures described in Sokal and Rholf (1995) using Program Statview (SAS Institute Inc., 1998). All mean values are presented with \pm 1 standard error.

\section{Results}

We recorded 1714 aboveground locations and activities for 49 individual marmots during the course of our observation sessions. When aboveground, marmots spent $26 \%$ of their time on the talus. The rest of their time (74\%) was spent in adjacent meadows (Fig. 1). Foraging was the most common activity (84\%) while marmots were in the meadows. Marmots foraged $11.6 \pm 0.4 \mathrm{~m}$ from the talus with a median distance of $5 \mathrm{~m}$ and a maximum distance of $115 \mathrm{~m}(n=3$ cases). The frequency at which marmots spent away from talus declined with increasing distance and sharply after the 5-m interval $(2.5-7.5 \mathrm{~m})$ (Fig. 1). The relative abundance of pellets was much greater at the $10-\mathrm{m}$ transect (0.71) compared with 20-m (0.17) and 30-m (0.12) transects (Fig. 1).

Marmot group sizes ranged from 2 to 36 marmots and the abundance of pellets ranged from 2 to 76 pellets per transect (Fig. 2). After natural logarithm transformation, marmot abundance was strongly and linearly related to the abundance of pellets within $10 \mathrm{~m}$ of the talus $\left(r^{2}=0.89, \mathrm{n}=14, P<0.001\right)$ (Fig. 2). The functional equation was: $\log _{\mathrm{e}}($ marmot abundance $)=1.51+0.76 \log _{\mathrm{e}}$ (pellet abundance), (S.E. regression coefficient $=0.07$ ).

We followed Krebs et al.'s (2001) procedure of multiplying predicted marmot abundance with a correction factor (CF) (Sprugel, 1983) to correct for the bias produced by $\log$-log regressions. The correction factor was calculated as: $\mathrm{CF}=\mathrm{e}^{(V / 2)}=\mathrm{e}^{(0.074 / 2)}=1.04$, where $V$ was the variance about the log-log regression. The corrected (solid 
line) and uncorrected (dashed line) regression formulas are plotted in Figure 2.

We tested our predictive equation of marmot abundance using pellet counts obtained from five social groups (average $12.6 \pm 1.4$ with range of 10 to 18 marmots per group) not used in the derivation of the relationship. Predicted marmot group sizes after applying the correction factor were on average 1.7 marmots less than the observed group sizes but not significantly (paired $t$-test: $t=1.5$, d.f. $=4, P=$ 0.21 ). Our estimates of marmot abundance averaged within $17 \pm 5 \%$ (range $=0-30 \%$ ) of the observed abundance.

\section{Discussion}

Fecal pellet counts are a suitable method for indexing marmot social group size. Pellet counts were strongly related to group size, including juveniles, in a simple relationship (Fig. 2) that, on average, predicted abundance within two marmots $(17 \%)$ of the observed group size. Pellet counting required considerably less time than total enumeration by live-trapping and observation (approximately $15 \mathrm{~min}$ per observer per social group versus approximately $10 \mathrm{~d}$ per observer per group respectively). The pellet index used the season's accumulation of feces and therefore was not subject to daily or seasonal changes in marmot behavior or abundance such as juvenile emergence or weather, which would impact other direct census methods.

When marmots were active aboveground, they spent the majority of their time in the meadows $(74 \%)$ mostly foraging $(84 \%$ of meadow activities) close $(11.6 \pm 0.4 \mathrm{~m})$ to talus edge (Fig. 1). The foraging distance that we measured was consistent with Barash's (1980) observations, where hoary marmots in Washington State foraged within 5 to $11 \mathrm{~m}$ of the talus. In Alaska, Holmes (1984b) reported that the mean foraging distance of hoary marmots from talus was $49.9 \pm$ $5.6 \mathrm{~m}$; however he recorded foraging distance in relation to talus that contained the sleeping burrow. In our study, we assumed that all talus contained a suitable refuge other than a sleeping burrow, which accounts for why our measurements of foraging distances are much less than those observed by Holmes (1984b). The distance from shelter to where marmots forage is influenced by predation risk (Holmes, 1984b; Carey and Moore, 1986; Kramer and Bonenfant, 1997). Since fecal pellet distribution was similar to marmot distribution in the meadows, fecal pellets may also be a suitable index of relative predation risk with distance from shelter. However, forage quality may also influence where marmots forage. Holmes (1984b) was able to manipulate where marmots concentrated their foraging by increasing the quality of forage by fertilization. These marmots reduced their foraging distance by constructing burrows in the fertilization plots thereby reducing predation risk. We would predict that changes in predation risk associated with new burrow construction would be reflected in changes in the fecal pellet distribution in these foraging meadows since forage intensity would increase near to the new shelter.

The specific functional relationship between fecal pellets and marmot abundance that we reported (Fig. 2) will probably not predict marmot abundance in other areas or predict the abundance of other marmot species because fecal deposition rates may be influenced by other factors such as diet quality, ecological or environmental conditions such that rates may differ between groups of animals. For example, Hodges (1999) found that the fecal deposition rates of wild snowshoe hares differed from those kept in captivity even while on a similar diet. Also, feces may not be easily detected in habitats where vegetation is tall and/or dense and feces are obscured. In our study site, the vegetation is short (approximately $5 \mathrm{~cm}$ ) and therefore marmot feces are easily observed. For accurate estimates of marmot abundance in other areas or in other species we strongly recommend that the functional relationship of marmot fecal pellets to marmot abundance be independently derived. However, if the goal of the study is to monitor the direction of population change or assess relative abundances of social groups within a region then the functional relationship is unnecessary. Pellet counts accurately reflect relative abundance of social groups within and among years and therefore provide a good index of relative changes in abundance. Without knowing the functional relationship, repeated pellet counts conducted in marmot social group territories can still be a valuable tool in long-term monitoring of population change.

Our testing of fecal counts as an index of marmot abundance was motivated by three potential applications. (1) Long-term population counts for North American marmots do not exist except for yellowbellied marmots (Marmota. flaviventris) in Colorado (Armitage, 1991, 1996) and Vancouver Island marmots (M. vancouverensis) on Vancouver Island, British Columbia (Bryant, 1996). The population status of any of the four other species of North American marmots $(M$. broweri, M. caligata, M. monax, and M. olympus) or status of yellowbellied marmots elsewhere than Colorado is virtually unknown. Presently we cannot assess the impact that climate change or other types of disturbance will have on marmot populations, especially in the absence of long-term monitoring programs. Evidence of climate change impacts on the annual timing of emergence of yellow-bellied marmots (Inouye et al., 2000) raises concern that other marmot populations will be affected as well. (2) Counting fecal pellets may be a simple method for long-term monitoring of the status of recovering or threatened marmot populations (North America - the Vancouver Island marmot [Janz et al., 2000]; Eurasia-black-capped marmot [ $M$. camtschatica], Mongolian marmot [M. sibirica], and others [see Bibikov, 1989]). Since counting fecal pellets is cost-efficient and rapid, monitoring marmots in this manner would require few resources. More colonies over larger areas could be monitored relatively quickly compared with live-trapping or observation-type census techniques. (3) The development of a simple index for monitoring population change in an alpine mammal presents the hoary marmot as a possible candidate to be an indicator species in alpine ecosystems. The hoary marmot is one of the most widespread alpine mammals ranging from Alaska south through Canada to Washington and Montana (Banfield, 1974). Commercially, they have little value in North America and therefore experience little direct human-related mortality in comparison with other alpine animals (e.g., ptarmigan [Lagopus spp.], sheep [Ovis spp.], mountain goats [Oreamnos americanus]) and therefore changes in their populations may be more representative of other large-scale impacts. Measuring changes in biodiversity in alpine ecosystems may be possible with only a handful of indicator species (Martin, 2001; Mac Nally and Fleishman, 2004). Indeed, the dynamics of marmot populations in the long-term may provide an indication of other changes in alpine snowpack, plant phenology and abundance, or predators.

\section{Acknowledgments}

For assistance in trapping and observing marmots, we thank Luc Barton, Julie Bernier, Catherine Gagnon, Gerda Ludwig, Shawn Morrison, Judy Muir, Layla Neufeld, and Tracey Smith. Funding was provided by the Natural Sciences and Engineering Research Council of Canada (NSERC), Environment Canada, the Wilburforce-Yellowstone to Yukon Science Grants Program, the Yukon Conservation Society, the Canadian Circumpolar Institute at the University of Alberta, the Northern Research Institute (Yukon College), the Department of Environment (Yukon), the Canada Research Chairs Program. TJK was supported by NSERC and Izaak Walton Killam fellowships. We thank the Arctic Institute of North America and Trans North Helicopters for logistical support throughout this study. 


\section{References Cited}

Armitage, K. B., 1991: Social and population dynamics of yellowbellied marmots: results from long-term research. Annual Review of Ecology and Systematics, 22: 379-407.

Armitage, K. B., 1996: Social dynamics, kinship, and population dynamics of marmots. In Le Berre, M., Ramousse, R., and Le Guelte, L. (eds.), Biodiversity in Marmots. International Network on Marmots, 113-128.

Arnold, W., 1990: The evolution of marmot sociality. II. Costs and benefits of joint hibernation. Behavioral Ecology and Sociobiology, 27: 239-246.

Banfield, A. W. F., 1974: The Mammals of Canada. Toronto and Buffalo: University of Toronto Press. 438 pp.

Barash, D. P., 1973: The social biology of the Olympic marmot. Animal Behaviour Monographs, 6: 171-245.

Barash, D. P., 1980: The influence of reproductive status on foraging by hoary marmots (Marmota caligata). Behavioral Ecology and Sociobiology, 7: 201-205.

Barnes, R. F. W., 2001: How reliable are dung counts for estimating elephant numbers? African Journal of Ecology, 30: 1-9.

Bibikov, D. I., 1989: Marmots. Moscow, U.S.S.R.: Agropromisdat. 255 pp.

Biggins, D. E., Miller, L., Hanebury, L., Oakleaf, R., Farmer, A., Crete, R., and Dood, A., 1993: A technique for evaluating blackfooted ferret habitat. In Oldenmeyer, J., Biggins, D., Miller, B., and Crete, R. (eds.), Management of prairie dog complexes for the reintroduction of the black-footed ferret. U.S. Fish and Wildlife Service Biological Report, 92(13), 73-88.

Blumstein, D. T. and Arnold, W., 1998: Ecology and social behavior of golden marmots (Marmota caudata aurea). Journal of Mammalogy, 79: 873-886.

Bryant, A. A., 1996: Reproduction and persistence of Vancouver Island marmots (Marmota vancouverensis) in natural and logged habitats. Canadian Journal of Zoology, 74: 678-687.

Carey, H. V. and Moore, P., 1986: Foraging and predation risk in yellow-bellied marmots. American Midland Naturalist, 116: 267-275.

Caughley, G. and Sinclair, A. R. E., 1994: Wildlife Ecology and Management. Cambridge: Blackwell Science. 334 pp.

Chitty, H., 1948: The snowshoe rabbit enquiry, 1943-46. Journal of Animal Ecology, 17: 29-44.

Chitty, H., 1950: The snowshoe rabbit enquiry, 1946-48. Journal of Animal Ecology, 19: 15-20.

Franken, R. J. and Hik, D. S., 2004: Influence of habitat quality, patch size and connectivity on colonization and extinction dynamics of collared pikas Ochotona collaris. Journal of Animal Ecology, 73: 889-896.

Fuller, T. K., 1991: Do pellet counts index white-tailed deer numbers and population change? Journal of Wildlife Management, 55: 393-396.

Hansen, R. M., 1975: Foods of the Hoary marmot on Kenai Peninsula, Alaska. American Midland Naturalist, 94: 348-353.

Hik, D. S., McColl, C. J., and Boonstra, R., 2001: Why are Arctic ground squirrels more stressed in the boreal forest than in alpine meadows. EcoScience, 8: 275-288.

Hochachka, W. M., Martin, K., Doyle, F., and Krebs, C. J., 2000: Monitoring vertebrate population using observation data. Canadian Journal of Zoology, 78: 527-529.

Hodges, K. E., 1999: Proximate factors affecting snowshoe hare movements during a cyclic population low phase. EcoScience, 6 : 487-496.

Holmes, W. G., 1979: Social behavior and foraging strategies of hoary marmots (Marmota caligata) in Alaska. Ph.D. thesis. University of Washington, Seattle. $130 \mathrm{pp}$.

Holmes, W. G., 1984a: The ecological basis of monogamy in Alaskan hoary marmots. In Murie, J. O. and Michener, G. R. (eds.), The Biology of Ground-Dwelling Squirrels. Lincoln: University of Nebraska Press, 250-274.

Holmes, W. G., 1984b: Predation risk and foraging behavior of the hoary marmot in Alaska. Behavioral Ecology and Sociobiology, 15: 293-301.

Hubbs, A. H., Karels, T., and Boonstra, R., 2000: Indices of population size for burrowing mammals. Journal of Wildlife Management, 64 296-301.

Inouye, D. W., Barr, B., Armitage, K. B., and Inouye, B. D., 2000: Climate change is affecting altitudinal migrants and hibernating species. Proceedings of the National Academy of Sciences, 97: 1630-1633.

Janz, D. W., Bryant, A. A., Dawe, N. K., Harper, B., Nagorsen, D., Doyle, D., deLaronde, M., Fraser, D., Lindsay, D., Leigh-Spencer, S., McLaughlin, R., and Simmons, R., 2000: National Recovery Plan for the Vancouver Island Marmot (Marmota vancouverensis): 2000 update. RENEW report; no 19, Vancouver Island Marmot Recovery Team (B.C.), Canadian Wildlife Service.

Johnson, C. N. and Jarman, P. J., 1987: Macropod studies at Wallaby Creek 6. A validation of the use of dung pellet counts for measuring absolute densities of populations of macropodids. Australian Wildlife Research, 14: 139-145.

Kramer, D. L. and Bonenfant, M., 1997: Direction of predator approach and the decision to flee to a refuge. Animal Behaviour, 54: 289-295.

Krebs, C. J., Boonstra, R., Nams, V., O’Donoghue, M., Hodges, K. E., and Boutin, S., 2001: Estimating snowshoe hare population density from pellet plots: a further evaluation. Canadian Journal of Zoology, 79: $1-4$.

Krebs, C. J., Gilbert, B. S., Boutin, S., and Boonstra, R., 1987: Estimation of snowshoe hare population density from turd transects. Canadian Journal of Zoology, 65: 565-567.

Lehmkuhl, J. F., Hansen, C. A., and Sloan, K., 1994: Elk pellet-group decomposition and detectability in coastal forests of Washington. Journal of Wildlife Management, 58: 664-669.

Litvaitis, J. A., Sherburne, J. A., and Bissonette, J. A., 1985a: A comparison of methods used to examine snowshoe hare habitat use. Journal of Wildlife Management, 49: 693-695.

Litvaitis, J. A., Sherburne, J. A., and Bissonette, J. A. 1985b. Influence of understory characteristics on snowshoe hare habitat use and density. Journal of Wildlife Management, 49: 866-873.

Lord, R. D., Vilches, A. M., Maiztegui, J. I., and Soldini, C. A., 1970: The tracking board: a relative census technique for studying rodents. Journal of Mammalogy, 51: 828-829.

Mac Nally, R. and Fleishman, E., 2004: A successful predictive model of species richness based on indicator species. Conservation Biology, 18: 646-654.

Martin, K., 2001: Wildlife communities in alpine and subalpine habitats. In Johnson, D. H. and O'Neil, T. A. (Managing Directors), Wildlife-habitat Relationships in Oregon and Washington. Corvallis: Oregon University Press, 239-260.

McArdle, B. H., Gaston, K. J., and Lawton, J. H., 1990: Variation in the size of animal populations: patterns, problems and artifacts. Journal of Animal Ecology, 59: 439-454.

Morneau, C. and Payette, S., 2000: Long-term fluctuations of a caribou population revealed by tree-ring data. Canadian Journal of Zoology, 78: $1784-1790$.

Murie, O. J., 1974: Animal Ttracks. Boston: Houghton Mifflin. $375 \mathrm{pp}$.

Neff, D. J., 1968: The pellet-group count technique for big game trend, census, and distribution: A review. Journal of Wildlife Management, 32: 597-614.

Owings, D. H. and Borchert, M., 1975: Correlates of burrow locations in Beechey ground squirrels. Great Basin Naturalist, 35: 402-404.

Rogowitz, G. L., 1988: Forage quality and use of reforested habitats by snowshoe hares. Canadian Journal of Zoology, 66: 20802083.

SAS Institute Inc., 1998: Statview 5.0. Cary, NC.

Schmutz, J. K. and Hungle, D. J., 1989: Populations of ferruginuous and Swainson's hawks increase in synchrony with ground squirrels. Canadian Journal of Zoology, 67: 2596-2601.

Sokal, R. R. and Rohlf, F. J., 1995: Biometry: the Principles and 
Practice of Statistics in Biological Research. 3rd ed. New York: W. H. Freeman. 887 pp.

Sprugel, D. G., 1983: Correcting for bias in log-transformed allometric equations. Ecology, 64: 209-210.

Van Horne, B., Schooley, R. L., Knick, S. T., Olson, G. S., and Burnham, K. P., 1997: Use of burrow entrances to indicate densities of Townsend's ground squirrels. Journal of Wildlife Management, 61: 92-101.

Vernes, K., 1999: Pellet counts to estimate density of a rainforest kangaroo. Wildlife Society Bulletin, 27: 991-996.

Wemmer, C., Kunz, T. H., Lundie-Jenkins, G., and McSea, W., 1996:
Mammalian sign. In Wilson, D. E., Cole, F. R., Nichols, J. D., Rudran, R., and Foster, M. S. (eds.), Measuring and Monitoring Biological Diversity: Standard Methods for Mammals. Washington, D.C.: Smithsonian Institution Press, 157-176.

Wilson, D. E., Cole, F. R., Nichols, J. D., Rudran, R., and Foster, M. S., 1996: Measuring and Monitoring Biological Diversity: Standard Methods for Mammals. Washington, D.C.: Smithsonian Institution Press. 409 pp.

Ms submitted September 2003 